\title{
An investigation into the prevalence, attitude and behaviour towards baby-led weaning practices in Ireland
}

\author{
A. Mezynska ${ }^{1}$, S. O'Keeffe ${ }^{2}$, M. Redmond ${ }^{3}$, K. O'Connor ${ }^{3}$ and J.L. O’Neill ${ }^{3}$ \\ ${ }^{1}$ Student of Human Nutrition (BSc), School of Agriculture, Food Science and Veterinary Medicine, Belfield, Dublin 4, \\ ${ }^{2}$ Student of Public Health Nutrition (BSc), School of Biological Health Sciences, Technological University Dublin, \\ Kevin Street, Co Dublin and \\ ${ }^{3}$ Danone Nutricia, Block 1, Deansgrange Business Park, Deansgrange, Co. Dublin
}

Adequate nutrition in infancy is a key factor that is required to support infants' rapid growth and weight gain. ${ }^{(1)}$ In Ireland, it is recommended for the introduction of complementary foods (also known as weaning) to start at around 6 months (but not before 17 weeks) and for it to be done in 3 stages, including a progression in textures as the stages move on. ${ }^{(1)}$ Observational evidence suggests that baby-led weaning (BLW) is becoming increasingly popular with parents and the media, but scientific research in this area is limited $^{(2)}$. The aim of this study was firstly to investigate the prevalence and parental attitudes and behaviors towards baby-led weaning (BLW) practices. Secondly, to examine healthcare professionals'(HCP) knowledge, attitudes and recommendations regarding BLW.

A sample of parents with a child aged 0-10 months old were recruited by the independent website Everymum.ie and completed a 23-item questionnaire online $(\mathrm{n}=933)$. An additional 15-item questionnaire was distributed to healthcare professionals $(\mathrm{n}=96)$. These participants were recruited at an educational seminar. Data was analysed using SPSS ${ }^{\circ}$ v26 (SPSS Inc., Chicago, Illinois, USA). Analysis included chi-square and descriptive statistics to calculate percentages.

Most parents were female (98\%), aged 25-34 years (50\%) and educated to third level $(82 \%)$. Over half $(55 \%)$ were first time parents. Of the HCP's $45 \%$ were midwives, $27 \%$ public health nurses, $8 \%$ practice nurses, $7 \%$ community nurses, $1 \%$ general practitioners and $12 \%$ others including parental educators. In the absence of a formal definition, $56 \%$ defined BLW as 'presenting baby with different foods, including puree and finger foods and letting them choose which ones they can explore and eat'. A large proportion ( $82 \%)$ stated that they discuss weaning practices with caregivers and of these only $16 \%(n=12)$ had completed formal training on BLW. None reported to actively discourage BLW.

Nearly half of parents $(49 \%)$ reported adopting the practice of BLW either all or some of the time. Over a third of participants who had begun weaning $(34 \%)(n=175)$, stated that they spoon-fed their baby $\leq 50 \%$ of the time.

While the study observed a high rate of breast-feeders overall (66\%), babies that were BLW were more likely to have been exclusively breastfed $(31 \%)$ than their non-BLW counterparts $(17 \%)(\mathrm{p} \leq 0.000)$. Additionally, only $11 \%$ of BLW parents stated that they were formula feeding their infants.

With a large proportion of parents in this study practising BLW to some degree, it strengthens the concept that BLW is increasing in popularity in Ireland, contrary to the national guidance on complementary feeding. Furthermore, a lack of training among healthcare professionals in this area is also evident. A clear definition of the term BLW and more research in this area, are essential so that national recommendations that are evidence based, can be established.

1. Food Safety Authority of Ireland (2011) Best Practice for Infant Feeding in Ireland, Second Edi. Dublin:

2. E. Dogan, G. Yilmaz, N. Caylan, et al. (2018), Pediatr. Int., 60, 12, 1073-1080. 